\title{
MULHERES NO PODER LEGISLATIVO: POSSIBILIDADES DE RESSIGNIFICAÇÃO ATRAVÉS DA TEORIA POLÍTICO-FEMINISTA DO CUIDADO
}

\author{
Women in legislative power: possibilities of re-signification trough the political-feminist \\ theory of care
}

Betina Fontana Piovesan

Resumo: Através da teoria político-feminista do cuidado, investiga-se a participação das mulheres na política, destacando-se o Poder Legislativo após a Constituição de 1988. Retomam-se as contribuições da teoria política feminista e seu desdobramento para uma ética do cuidado e analisam-se as cotas por gênero, cujo desempenho é examinado através dos dados das eleições no período. Tem-se como problema a baixa participação política de mulheres, que aponta para a eficácia limitada das cotas de gênero. Como hipótese, tem-se que as cotas aumentariam a participação feminina na política. Utilizou-se a metodologia de estudo qualitativo, exploratório e descritivo, de levantamento bibliográfico e documental, com procedimento de revisão de literatura narrativa e análises de dados. Como conclusão, percebeu-se que as demandas e experiências das mulheres permanecem negligenciadas, inclusive quando se institui um mecanismo jurídico de pretensa inclusão. Assim, o resultado alcançado é da manutenção do status quo, conferindo ao direito e à política um caráter patriarcal que ignora o cuidado como valor político central, inviabilizando uma democracia radical. Finalmente, alerta-se para a necessidade de adoção de práticas redistributivas das atividades de cuidado desconstrução dos padrões de masculinidade, construção de novas narrativas de responsabilidade, considerando interdependências e vulnerabilidades nas relações sociais e nos espaços públicos.

Palavras-chave: Participação política. Teoria político-feminista. Ética do cuidado. Cotas. Democracia.
Abstract: Through the political-feminist theory of care, the participation of women in politics are investigated, highlighting the Legislative Power after the 1988 Constitution. The contributions of feminist political theory are resumed to an ethics of care. The performance of gender quotas is analyzed through data from the elections in the period. The main problem of this study is to analyze the low political participation of women, which points to the limited effectiveness of gender quotas. As a hypothesis, it is assumed that the quotas would increase women's participation in politics. The methodology used was a qualitative, exploratory and descriptive study, a bibliographical and documentary survey, with a narrative literature review procedure and data analysis. As a conclusion, the women's demands and experiences remain neglected, including when establishing a legal mechanism of pretentious inclusion. Thus, the result achieved is the maintenance of the status quo, giving law and politics a patriarchal character that ignores care as a central political value, rendering a radical democracy unfeasible. Finally, it is necessary to adopt redistributive practices of care activities, deconstruction of masculinity patterns, construction of new narratives of responsibility, considering interdependencies and vulnerabilities in social relations and in public spaces.

Keywords: Political Participation. Political-feminist theory. Ethic of care. Quotas. Democracy.

Artigo recebido em 15 jul. 2019 e aprovado em 13 ago. 2019. 


\section{Introdução}

No dia 14 de março de 2018 os noticiários do mundo pararam para anunciar a morte de Marielle Franco, a quinta vereadora mais votada do Rio de Janeiro, que se envolvia abertamente com pautas de direitos humanos. Sua execução suspeita e até agora não solucionada (julho de 2019), segue repercutindo e levando milhares de manifestantes em luto e em luta às ruas do país e do mundo.

No ano de 2016, a primeira mulher eleita à presidência do Brasil foi alvo de um impeachment. Dentre outros fatores, o que se sustentava era que ela "não sabia fazer política". Os ataques misóginos a sua honra, sua aparência, sua sexualidade e sua vida pessoal permearam todo o processo. Já em fevereiro de 2018, pouco antes do grande movimento $8 \mathrm{M}$, que mobilizou milhões de mulheres pelo mundo, deu-se a seguinte situação na Assembleia Legislativa do Estado de Santa Catarina: um deputado, ao debater uma proposta legislativa no plenário se dirigiu à deputada Ana Paula Lima com os seguintes dizeres "gostaria de debater com seu marido, que é homem"1.

O que os três casos anteriormente narrados têm em comum? Todas essas mulheres que ousaram ocupar um espaço na política institucional, foram vítimas de violências e machismos. E os exemplos não são raros. Os casos de Marielle, Dilma e Ana Paula não se configuram como exceções. Portanto, há uma dificuldade extra que se manifesta quando as mulheres decidem participar da esfera política.

Nesse sentido, o tema deste artigo é a participação política das mulheres, cujo problema que visa investigar são os limites e as possibilidades do instituto da cota de gênero na política. O recorte metodológico dar-se-á na análise do Poder Legislativo após a Constituição Federal de 1988, com especial enfoque na Câmara de Deputados, mas também analisando as demais casas de forma secundária. A pesquisa perfaz-se em um estudo qualitativo, exploratório e descritivo, a partir de levantamento bibliográfico e documental, com procedimento de revisão de literatura narrativa. Para tanto, trabalhar-se-á sob a hipótese de que as cotas para mulheres na política contribuem para aumentar e melhorar sua efetiva participação.

\footnotetext{
1 https://catarinas.info/deputada-catarinense-e-alvo-de-misoginia-em-plenario/ Acesso em: 10 jul. 2019.
} 
O objetivo do artigo é demonstrar que a participação das mulheres na política, ainda que o ordenamento jurídico brasileiro preveja institutos de pretensa inclusão, segue uma lógica patriarcal de dominação masculina que desconsidera as demandas das mulheres. Essa investigação será feita sob a perspectiva teórico-metodológica da ética do cuidado.

Para tanto, no primeiro momento, serão feitas breves considerações sobre os movimentos feministas, com seus encontros e desencontros, mas com o mote geral de valorização às experiências atentando para as opressões cruzadas, num processo de interseccionalidade para superação das discriminações e violências a que estão submetidas as mulheres. Como consequência, trabalhar-se-á com as contribuições do feminismo para uma teoria política, que tem como um de seus desdobramentos a ética do cuidado.

Em seguida, será analisado o desempenho das cotas brasileiras, através de dados obtidos junto ao Tribunal Superior Eleitoral em relação às eleições que ocorreram para os cargos legislativos no país desde a promulgação da Constituição de 1988.

Por fim, mobilizar-se-á a teoria política do cuidado para aplicá-la ao desempenho obtido na investigação de dados. Isto é, analisar-se-á em que medida a participação das mulheres na política, que atualmente se dá através das cotas, é pensada de acordo com o cuidado como um valor central, permitindo o desenvolvimento das capacidades e da agência autônoma das mulheres, considerando suas vulnerabilidades e interdependências, e em que medida determina assunção de responsabilidades e se opõe às práticas opressivas e de subordinação.

\section{Teoria política feminista}

O feminismo enquanto teoria política é um movimento de investigação social que opera através de uma reflexão crítica da sociedade a partir da desigualdade de gêneros. Portanto, busca compreender como se estruturam os mecanismos de poder que seguem reproduzindo a dominação masculina e a consequente sujeição das mulheres (MIGUEL; BIROLI, 2014). Em outras palavras, o feminismo pode ser compreendido "como o desejo por democracia radical voltada à luta por direitos daqueles que pade- 
cem sob injustiças que foram armadas sistematicamente pelo patriarcado"2 (TIBURI, 2018, p. 12).

Ainda que haja narrativas divergentes, de modo geral, compreende-se como primeira onda do feminismo a reivindicação do direito ao voto e à educação. O movimento, portanto, traduzia-se na luta pelo direito à cidadania. No Brasil, essa conquista ocorreu em 1932. Vale dizer que era um movimento essencialmente branco, elitizado e burguês, portanto, não contemplava toda a pluralidade de mulheres.

Mesmo com a adoção do sufrágio universal, os avanços na participação política das mulheres foram pouco significativos. O direito ao voto introduziu as mulheres a uma cidadania formal, mas não substancial. De igual forma, mesmo com mais acesso à educação em todos os níveis, poucos foram os progressos na condição das mulheres na sociedade, que permaneceram restrita ao ambiente doméstico, ou com profissões de menor prestígio e remuneração (OLIVEIRA, 1999).

Tornou-se necessário, portanto, identificar os recursos de opressão/dominação mais profundos do que a restrição consignada em lei, o que culminou no desenvolvimento da segunda onda da agenda feminista, que procurou evidenciar a importância da vida privada, apontada como o berço das desigualdades entre homens e mulheres. Se na onda anterior as atenções eram voltadas à esfera pública, para a qual se buscava a possibilidade de as mulheres fazerem parte, na segunda fase as feministas passaram a enfrentar de forma política questões eminentemente privadas, tais como sexualidade, direitos reprodutivos, estupro marital e divisão desigual do trabalho do-

\footnotetext{
2 Adota-se para este trabalho a corrente de Márcia Tiburi, trabalhando-se com o termo patriarcado. Apesar de não ser consenso entre teóricas feministas - Ilze Zirbel (2016) e outras teóricas do cuidado preferem trabalhar com a palavra androcentrismo (que significa a representação do mundo unicamente através das experiências e opiniões de homens transformando-as em norma universal, enquanto Luis Felipe Miguel e Flávia Biroli (2014) trabalham com dominação masculina -, vai-se de encontro ao que Carole Pateman (1993) já apontou: patriarcado é uma forma de dominação política. Trata-se de relações de subordinação e dominação coletivizadas em estruturas impessoais que distribuem vantagens e oportunidades em prejuízo do gênero feminino; os homens estão sempre no polo dominante, e, as mulheres, no polo dominado. Nada mais é do que a subordinação/sujeição das mulheres. No Dicionário Crítico do Feminismo (2009, p. 176), "o patriarcado designa uma formação social em que os homens detêm o poder, ou ainda, mais simplesmente, o poder é dos homens". Por isso, patriarcado se mostra o termo mais adequado para analisar a participação política das mulheres. Além disso, a opção pelo uso de patriarcado se dá pela ferramenta retórica e pelo valor simbólico que ele desempenha.
} 
méstico, determinantes para sua sujeição. Assim, rejeitava-se qualquer apelo a preferências naturais ou biológicas das mulheres para a vida doméstica, bem como argumentos sobre incapacidades para a vida pública. Com a emblemática frase de Simone de Beauvoir (1908-1986), "Não se nasce mulher, torna-se", o feminismo reemerge com a crítica feminista à naturalização de papéis socialmente construídos, reafirmando que "nenhuma determinação biológica, psicológica ou econômica pesa sobre a mulher senão por razões culturais" (SANTOS, 2014, p. 145). No Brasil, o movimento seguiu a tendência plural e esteve imerso nas questões políticas e nos desdobramentos da Ditadura Militar. Suas demandas, contudo, colocavam em tensão a dicotomia público/privado e questionavam a naturalização dos papéis socialmente atribuídos às mulheres.

As feministas de primeira onda eram mulheres essencialmente brancas e letradas, pertencentes à elite, ao passo que a segunda onda do movimento permaneceu dominada por mulheres de classe média. Evidenciou-se, portanto, no final do século XX e no início do século XXI, que o movimento feminista vinha sendo excludente, porque as mulheres não são iguais aos homens, tampouco entre si. A terceira onda, com um caráter antiessencialista e atento às transversalidades de gênero "abrange as tentativas de desconstrução da categoria "mulher" como um sujeito coletivo unificado que partilha as mesmas opressões, os mesmos problemas e a mesma história. Trata-se de reivindicar a diferença dentro da diferença" (SIQUEIRA, 2015, p. 337). No Brasil, a terceira onda feminista acompanha o cenário internacional e emerge no contexto da Constituição de 1988.

As contribuições dos movimentos feministas, plurais e diversos, oferecem subsídios importantes para uma teoria política feminista, não se limitando somente a uma ideologia ou a um movimento desarticulado. Nenhuma reflexão comprometida sobre teoria política, justiça e democracia pode ignorar os ensinamentos da teoria feminista, tampouco desconsiderar o impacto do gênero nas relações sociais, inclusive nas consequências para o direito e as leis.

A teoria política feminista, que se aperfeiçoou ao longo de sua história e de acordo com o desenvolvimento das três ondas, oferece pressupostos que mantêm uma tensa relação com as teorias políticas tradicionais, especialmente o liberalismo, posto que um de seus primeiros ensinamentos é a desconfiança do sujeito universal, visto que aceitar a ideia de sua existência importa em abstrair as diferenças hierárquicas nas sociedades (MIGUEL; BIROLI, 2014, p. 9). 
Assim, ao falar da teoria política feminista, deve-se ter em mente: 1) a desconfiança do sujeito universal; 2) a reflexão crítica sobre dualismos hierarquizantes, notadamente público/privado; 3) a atenção às opressões cruzadas, considerando as intersecções entre diversos marcadores sociais (raça, classe, gênero, etnia, localização geográfica, sexualidade, idade, etc.); e 4) a valorização ao ponto de vista e à experiência vivida.

Portanto, questionar premissas básicas das hierarquias sociais e do funcionamento das instituições, além de desenvolver novas práticas e justificativas para as instituições e as práticas político-sociais é o desafio da teoria feminista, bem como de uma teoria política feminista do cuidado.

\section{1 Ética do cuidado como uma teoria política feminista}

Como visto, um dos desdobramentos do pensamento feminista é a afirmação de que existem diferenças entre homens e mulheres, sejam históricas, culturais, sociais ou até mesmo biológicas, que não justificam, contudo, tratamentos discriminatórios. Apesar disso, essas diferenças foram usadas para confinar as mulheres ao espaço privado. Esse banimento das mulheres à vida doméstica, por sua vez, contribuiu para o desenvolvimento de uma experiência singular, baseada no cuidado e na gestão dos afetos (MIGUEL; BIROLI, 2014, p. 36). Assim, "homens e mulheres passaram a ser associados com modos diferentes de pensamento e sentimento" (KYMLICKA, 2006, p. 339).

Uma das primeiras teóricas a perceber o resultado dessa diferença foi Carol Gilligan. Insatisfeita com o caráter androcêntrico ${ }^{3}$ dos resultados das pesquisas existentes sobre o desenvolvimento moral humano, especialmente de Lawrence Kohlberg ${ }^{4}$, com quem chegou a trabalhar, Gilligan publicou a sua crítica em 1982, intitulada Uma voz, diferente: teoria psicológica $e$ desenvolvimento da mulher. Em seus estudos, Gilligan passou a "incluir as experiências, preocupações e modos de pensar das mulheres" (ZIRBEL, 2016, p. 40), obtendo como resultado que o raciocínio feminino, de modo geral, "denotava uma preocupação com o contexto relacional de onde os

\footnotetext{
${ }^{3}$ Zirbel define o termo androcentrismo como a prática, consciente ou não, de representar o mundo unicamente através das experiências e das opiniões de homens, transformando-as em normal universal.

${ }^{4}$ Foi um pesquisador da Universidade de Chicago e trabalhou desde a década de $1950 \mathrm{com}$ pesquisa empírica para a elaboração uma teoria do desenvolvimento moral humano, que procurava explicar como seres humanos julgam o que é certo ou errado ao longo de suas vidas e como efetuam mudanças de julgamentos.
} 
problemas emergiam e uma tendência a redefinir tais problemas a favor da preservação das relações interpessoais" (ibid.). Tratava-se, pois, da Ética do Cuidado.

Com os resultados de suas pesquisas, Gilligan pode concluir que as mulheres foram ignoradas como objeto e sujeitos de análise, tiveram suas experiências definidas como intuitivas e não racionais, decorrentes de uma questão natural, enquanto os homens foram priorizados como "objeto de estudo e modelo ideal" (ibid.). A moralidade ligada ao feminino foi, portanto, silenciada em detrimento da voz masculina que se direciona para o desenvolvimento de propostas éticas pautadas em princípios imparciais e direitos (KUHNEN, 2010, p. 156). O paradigma alternativo de resolução de problemas morais, foi nomeado por Gilligan de "voz diferente".

Para explicar essa moralidade diferente, evidenciando as inconsistências das teorias então existentes, Gilligan utilizou-se de uma "estratégia de contraste" (ZIRBEL, 2016, p. 43/44), contrapondo a ética do cuidado à ética da justiça. A ética da justiça está associada a princípios corretos e universais, porém abstratos, e tem como objetivo a universalidade e a imparcialidade. Ainda, é por vezes apontada como uma forma de responder "unicamente antes à humanidade comum das pessoas que à individualidade distinta das pessoas". A justiça, dessa forma, interessa-se pelo outro generalizado e negligencia o outro concreto (KYMLICKA, 2006, pp. 352/353).

Sintetizando o pensamento de Gilligan, Kymlicka (2006, p. 356) aponta que a distinção por ela oferecida "é que o raciocínio de justiça pensa no interesse dos outros em termos de respeitar reivindicações de direitos, ao passo que o raciocínio do cuidado pensa no interesse dos outros em termos de aceitar responsabilidades" que, por sua vez, importa em "algum interesse positivo pelo seu bem-estar". A voz padrão, comumente associada ao masculino, lida com direitos que "são essencialmente mecanismos de autoproteção que podem ser respeitados simplesmente deixando as outras pessoas em paz. (ibid.). Joan Tronto (2007, p. 103), por sua vez, dissociou o cuidado de fatores psicológicos, afastou-o da esfera familiar e conceituou-o como um valor político, definindo por "Uma atividade genérica que compreende tudo o que fazemos para manter, perpetuar e reparar nosso mundo, afim de que possamos viver nele tão bem quanto possível. Esse mundo compreende nossos corpos, nós mesmos e nosso meio ambiente, tudo o que tentamos manter interligado em uma complexa rede que dá suporte à vida". O cuidado como uma questão política é "uma variedade de ativida- 
des destinadas a manter, perpetuar e reparar o mundo no qual vivemos". Para que seja assim encarado, é necessário, primeiramente, compreender e definir o sujeito que lhe serve de base: aquele vulnerável e interdependente (ZIRBEL, 2016, p. 133 e 174).

Se por um lado a teoria feminista tece severas críticas ao sujeito universal do liberalismo, aquele autossuficiente e autointeressado, contraditoriamente, por outro, teóricos "atrelados à ética do cuidado referem-se constantemente à ideia de uma condição humana universal que, por sua vez, orienta as práticas e valores do cuidado" (ZIRBEL, 2016, p. 135). Para a ética do cuidado, a universalidade é evidenciada na vulnerabilidade e na dependência, comuns à condição e às experiências humanas. Surpreendentemente, para esse desenvolvimento moral, elas não são condições negativas, mas algo que remete "à dimensão relacional de uma existência marcada por um conjunto de necessidades e capacidades físicas, cognitivas e sociais que demandam cuidado e interações interpessoais complexas ao longo de toda a vida" (ZIRBEL, 2016, p. 139). Por isso, características importantes e comuns a todos e a todas, em maior ou menor medida, são a vulnerabilidade e a interdependência. Enquanto sujeitos corpóreos e finitos, temos dependências de toda ordem: essa é uma condição humana universal, que implica em assunção de obrigações e responsabilidades.

O cuidado é, no fim, o conjunto de atividades destinadas a atender as necessidades vitais biológicas, a responder as necessidades individuais, a minimizar e evitar danos e sofrimentos desnecessários, auxiliar a desenvolver capacidades e habilidades, devendo ser executadas de maneira atenta, responsiva e engajada, com respeito às vulnerabilidades e às dependências (ZIRBEL, 2016, pp. 175-176).

Fica claro, portanto, que, ao contrário das críticas tecidas à ética do cuidado, ela não reforça estereótipos de gênero, tampouco o pensamento maternal, porque independe da "presença de certas emoções (simpatia, bondade, compaixão) para motivar a ação ou considerá-la correta” (ibid.). O cuidado pode ser também definido por aquilo que ele não é. Basicamente, Zirbel (2016) pontua que o cuidado é o inverso das práticas opressivas, subordinativas e violentas. A autora faz, então, uma (re)construção histórica para explicar por que ele se dissocia do masculino, já que "ao serem recrutados pela cultura para serem violentos, meninos e homens são conclamados não apenas a deixar de agir de acordo com certo modelo de cuidado, mas de agir de maneira oposta a ele" (ZIRBEL, 2016, p. 209). 
Ao contrário das mulheres, os homens não estão associados a uma ideia de cuidado, mas sim de autossuficiência, independência, controle e dominação, especialmente das instituições políticas. Os homens, portanto, detêm os atributos necessários para a vida pública, que depende da exclusão das mulheres para o seu bom funcionamento (KYMLICKA, 2006, p. 339).

Ao compreender o cuidado para além das relações de proximidade e de maneira coletiva, ele passar a ser encarado como um valor político capaz de redefinir as instituições públicas. Assim sendo, dar-se-á um salto para compreender como se apresentam os mecanismos jurídicos atualmente e quais são as regras que regem o sistema eleitoral, a fim de, posteriormente, analisar em que medida o Estado Democrático de Direito é pensado de acordo com as interdependências e vulnerabilidades, mediante a redistribuição de responsabilidades pelas atividades de cuidado, proporcionando uma efetiva participação das mulheres na política institucional.

\section{O desempenho das cotas no Brasil}

Se para o filósofo grego Aristóteles "o homem é um animal político”, as feministas, por meio de suas lutas, já conseguiram provar que as mulheres são também seres políticos, com igual capacidade de exercer papéis e funções no espaço público.

A noção de uma democracia radical ${ }^{5}$ é aquela em que as minorias (políticas e não numéricas), como é o caso das mulheres, tenham suas demandas atendidas e suas particularidades respeitadas, inclusive e especialmente no que tange à participação na política institucional ${ }^{6}$. Ora, se a lei e o direito afiguram-se como modeladores do comportamento social, parece óbvio que o seu controle não seja monopolizado por somente um grupo (homens, brancos, meia idade, proprietários/classe média, que se apresentam como heterossexuais). A igualdade na participação política é uma premissa democrática, de modo que a participação da mulher na política, no exercício dos cargos eletivos é indicadora da qualidade da democracia (MOISÉS; SANCHEZ, 2014, p. 89).

\footnotetext{
${ }^{5}$ Política institucional é o termo utilizado para caracterizar um amplo campo de reflexão que toma as instituições sociais como protagonistas, analisa o grau de suas práticas e a interação constante com o indivíduo. Constitui uma análise predominantemente descritiva e/ou jurídica do fenômeno. (COUTO, 2015, p. 480)

${ }^{6}$ De acordo com Araújo (2014, p. 26), “a representação simbólica remete, entre outros aspectos, ao estímulo que a presença de mulheres pode conferir para que outras mulheres se habilitem a disputar e participar da política".
}

Resenha Eleitoral (Florianópolis), v. 23, n. 1, p. 231-262, 2019 
No contexto jurídico político, dentre outros, tem relevância a participação feminina na Assembleia Constituinte de 87, que culminou na promulgação da Constituição da República Federativa do Brasil de 1988, bem como as recomendações internacionais da IV Conferência Mundial sobre a Mulher, em Beijing, 1995.

Por consequência, as cotas para mulheres na política institucional foram inseridas no ordenamento jurídico e político brasileiro geral a partir das eleições proporcionais de 1998, com a promulgação da Lei 9.504 de 1997 que, após alterações, determina aos partidos políticos o percentual mínimo de $30 \%$ de candidaturas femininas nas eleições proporcionais aos cargos do Poder Legislativo (Câmara de Deputados, Assembleias Legislativas e Câmara de Vereadores).

Dessa forma, a fim de analisar o desempenho do instituto das cotas nas eleições brasileiras, serão investigados os dados da Câmara de Deputados, seja no que tange ao número de candidatas e candidatos lançados por eleição, seja no que se refere ao número de parlamentares efetivamente eleitos. Para tanto, serão observadas as eleições que ocorreram no país desde a promulgação da Constituição Federal de 1988, para que se estabeleça um contraponto entre o período em que não existiam as cotas e o período em que estas passaram a incidir nas eleições.

A análise deter-se-á a esta casa legislativa pois, num primeiro momento, acredita-se que por ser o parlamento federal que as cotas atingem, a Câmara de Deputados deve refletir os percentuais estaduais e municipais. Ou seja, a Câmara de Deputados deve ser um espelho e modelo a ser seguido, apresentando-se como um paradigma nacional.

Entretanto, a fim de confirmar a hipótese, serão também examinados os dados gerais relativos às Assembleias Legislativas e às Câmaras de Vereadores, exclusivamente no que tange ao percentual de mulheres lançadas como candidatas.

Por fim, o percentual de mulheres candidatas ao Senado Federal também será observado com o objetivo de verificar se as cotas por gênero incidentes no preenchimento de candidaturas cumprem sua pretensão, que é de aumentar a participação das mulheres na política. Vale lembrar que as eleições para senadora e senador não têm a incidência das cotas.

Feitas essas considerações, passa-se à disposição das tabelas. 


\subsection{A participação política das mulheres no poder legislativo nacional: o paradigma da Câmara de Deputados}

Tabela 01: Percentual de Mulheres Candidatas para a Câmara de Deputados a partir da Constituição de 1988 até o ano de 2018

\begin{tabular}{|c|c|c|c|}
\hline Ano & $\begin{array}{c}\text { Total de Candidatos } \\
\text { em números } \\
\text { absolutos }\end{array}$ & $\begin{array}{c}\text { Candidatas } \\
\text { Mulheres em } \\
\text { números absolutos }\end{array}$ & $\begin{array}{c}\text { Percentual de } \\
\text { Candidatas em } \\
\text { Relação ao Total }\end{array}$ \\
\hline 1990 & 3.827 & 229 & 5,98 \\
\hline 1994 & 3.008 & 185 & 6,15 \\
\hline 1998 & 3.417 & 353 & 10,33 \\
\hline 2002 & 4.289 & 490 & 11,42 \\
\hline 2006 & 4.961 & 630 & 12,69 \\
\hline 2010 & 4.904 & 935 & 19,06 \\
\hline 2014 & 6.178 & 1.796 & 29,07 \\
\hline 2018 & 8.226 & 2.603 & 31,64 \\
\hline
\end{tabular}

Fonte: Autora. Adaptação feita com base nos dados de 2018 do Tribunal Superior Eleitoral.

A Tabela 01 refere-se às eleições compreendidas entre os anos de 1990 e 2018 para o cargo de deputada e deputado federal. Inicialmente, foram reunidos os dados relativos ao número absoluto do total de candidatos e candidatas. Em seguida, o número absoluto de candidatas mulheres e, por fim, o percentual de candidatas mulheres em relação ao número total de candidatos. Os dados constantes da quarta coluna é que interessam na análise do desempenho das cotas, já que, de acordo com o texto legal, estas devem incidir justamente no percentual de mulheres candidatas.

Nas eleições de 1990 e 1994 não houve incidência das cotas, pois a lei é de 1997. Inclusive, foram os anos em que o percentual de mulheres candidatas apresentou o pior desempenho. Ademais, pela análise da tabela 01, percebe-se que, desde 1998, quando as cotas já estavam implementadas, ocorreu um aumento de candidatas mulheres em termos de números absolutos, mas o percentual determinado em lei só foi respeitado vinte anos depois, em 2018. Assim, pode-se afirmar que as cotas serviram de estímulo à candidatura de mais mulheres, tendo em vista o aumento do número de candidatas. Entretanto, o número de candidatos homens também aumentou.

O aumento no número de candidatas em termos absolutos, contudo, acompanha, ainda que não proporcionalmente, o crescimento popuResenha Eleitoral (Florianópolis), v. 23, n. 1, p. 231-262, 2019 
lacional. De acordo com o IBGE, desde 1970 a população brasileira vem crescendo, de modo que as mulheres sempre representaram a maioria dos habitantes do país. Ou seja, há mais mulheres candidatas porque há mais mulheres compondo a população brasileira.

Também vale lembrar que não há sanção legal para o partido que descumpre o percentual fixado por lei, em que pese haver decisões do Tribunal Superior Eleitoral cassando mandatos de parlamentares eleitos por partidos que descumprem a determinação. Assim, se o objetivo geral das cotas era estimular a participação das mulheres na política, em termos percentuais pode-se dizer que a lei falhou nesse quesito, já que o aumento no percentual de candidatas parece ter mais relação com o crescimento populacional em si, do que com a existência do mecanismo jurídico de suposta inclusão. Também é necessário destacar o fato de que, no ano de 2014, quando houve o maior aumento no percentual de candidatas à Câmara de Deputados, no âmbito do executivo, reelegia-se a primeira mulher a presidir o país, Dilma Rousseff. Assim, após ter cumprido seu primeiro mandato (2010-2014) e se lançar à reeleição, a ex-presidenta obteve a maioria de votos e foi novamente eleita para o cargo. Ainda que não se possa estabelecer uma relação direta, serão vistos adiante os impactos das candidaturas femininas para encorajar outras mulheres a candidatarem-se aos cargos eletivos, o que é chamado de representação simbólica? ${ }^{7}$.

\footnotetext{
${ }^{7}$ De acordo com Bueno e Costa (2018, p. 63), por candidatura fraudulenta compreende-se a conduta de tentar driblar a regra legislativa que impõe uma porcentagem mínima de candidaturas de cada gênero, através do registro de nomes de mulheres que preenchem a lista, mas não têm a candidatura estimulada. Por vezes, sequer sabem que seu nome foi apresentado. São chamadas "candidaturas de mulheres laranja". Essa conduta foi definida como fraude pelo TSE no julgamento do Recurso Especial no 149 , originário do Piauí, cuja ementa consignou, in verbis: RECURSO ESPECIAL. AÇÃO DE IMPUGNAÇÃO DE MANDATO ELETIVO. CORRUPÇÃO. FRAUDE. COEFICIENTE DE GÊNERO.1. Não houve violação ao art. 275 do Código Eleitoral, pois o Tribunal de origem se manifestou sobre matéria prévia ao mérito da causa, assentando o não cabimento da ação de impugnação de mandato eletivo com fundamento na alegação de fraude nos requerimentos de registro de candidatura.2. O conceito da fraude, para fins de cabimento da ação de impugnação de mandato eletivo (art. 14, \10, da Constituição Federal), é aberto e pode englobar todas as situações em que a normalidade das eleições e a legitimidade do mandato eletivo são afetadas por ações fraudulentas, inclusive nos casos de fraude à lei. A inadmissão da AIME, na espécie, acarretaria violação ao direito de ação e à inafastabilidade da jurisdição. Recurso especial provido (TSE, RESPE 149, julgamento em 04.08.2015).
} 
Uma segunda análise que se torna necessária a fim de compreender a (in)eficácia das cotas e, mais ainda, os limites da atuação da mulher na política institucional, é o percentual de mulheres eleitas. Isto é, das vagas disponíveis na Câmara de Deputados, quantas efetivamente são ocupadas por candidatas mulheres.

Tabela 02: Percentual de Mulheres Eleitas para a Câmara de Deputados a partir da Constituição de 1988 até o ano de 2018

\begin{tabular}{|c|c|c|c|}
\hline Ano & $\begin{array}{c}\text { Total de Eleitos em } \\
\text { números absolutos }\end{array}$ & $\begin{array}{c}\text { Eleitas Mulheres } \\
\text { em números } \\
\text { absolutos }\end{array}$ & $\begin{array}{c}\text { Percentual de } \\
\text { Mulheres Eleitas em } \\
\text { Relação ao Total }\end{array}$ \\
\hline 1990 & 503 & 30 & 5,96 \\
\hline 1994 & 513 & 38 & 7,40 \\
\hline 1998 & 513 & 29 & 5,65 \\
\hline 2002 & 513 & 42 & 8,18 \\
\hline 2006 & 513 & 45 & 8,77 \\
\hline 2010 & 513 & 45 & 8,77 \\
\hline 2014 & 513 & 54 & 10,52 \\
\hline 2018 & 513 & 77 & 15,00 \\
\hline
\end{tabular}

Fonte: Autora. Adaptação feita com base nos dados de 2018 do Tribunal Superior Eleitoral.

A Tabela 02 segue examinando a Câmara de Deputados desde 1990 até 2018. Portanto, analisaram-se o número de cadeiras disponíveis na casa parlamentar; em seguida, o número absoluto de mulheres eleitas, ou seja, de cada vaga, quantas são efetivamente ocupadas por mulheres para, ao fim, estabelecer um percentual de mulheres em relação ao total. Nesse sentido, a segunda consideração que merece destaque é o número percentual de mulheres eleitas.

Observa-se que as eleitas ao longo dessas eleições representaram apenas 15\% (quinze por cento), e somente nas últimas eleições à Câmara de Deputados. O percentual é ainda muito baixo e passa longe da previsão legal que, repita-se, determina a candidatura de, pelo menos, 30\% (trinta por cento) de mulheres.

Novamente constata-se a falha do instituto jurídico de suposta inclusão, tendo em vista que garantir a reserva mínima de candidaturas praticamente não interfere no número efetivo de deputadas federais representantes eleitas. Em outras palavras, significa dizer que lançar mulheres como candidatas pouco impacta na questão da eleição, como se infere da tabela a seguir. 
Tabela 03: Percentual de Eleitas em relação ao número de Mulheres Candidatas para a Câmara de Deputados a partir da Constituição de 1988 até o ano de 2018

\begin{tabular}{|c|c|c|c|}
\hline Ano & Candidatas & Eleitas & $\begin{array}{c}\text { Percentual de Eleitas } \\
\text { em relação ao Total } \\
\text { de Candidatas }\end{array}$ \\
\hline 1990 & 229 & 30 & 13,10 \\
\hline 1994 & 185 & 38 & 20,54 \\
\hline 1998 & 353 & 29 & 8,21 \\
\hline 2002 & 490 & 42 & 8,57 \\
\hline 2006 & 630 & 45 & 7,14 \\
\hline 2010 & 935 & 45 & 4,81 \\
\hline 2014 & 1.724 & 54 & 3,13 \\
\hline 2018 & 2.603 & 77 & 2,95 \\
\hline
\end{tabular}

Fonte: Autora. Adaptação feita com base nos dados de 2018 do Tribunal Superior Eleitoral.

A Tabela 03 refere-se ao percentual de mulheres eleitas em relação ao número de candidatas. Isto é, das mulheres que se lançam como candidatas ao cargo de deputada federal, quantas efetivamente conseguem se eleger. A análise ainda se refere à Câmara de Deputados no período compreendido entre as eleições de 1990 e 2018. Primeiramente, foram colhidos os dados do número total de candidatas; em segundo, o número de eleitas; e, por fim, estabeleceu-se um percentual entre a primeira e a segunda coluna.

Ocorre que a Tabela 03 revela dados ainda piores em relação às anteriores. Novamente, a lei não cumpre seu objetivo de incentivar a participação da mulher na política pois, mesmo havendo um aumento no número absoluto de candidatas mulheres ao parlamento federal, destas, nem mesmo $10 \%$ (dez por cento) são eleitas. Ora, já foi visto na tabela 01 que mais mulheres passaram a candidatar-se. O crescimento populacional, as mudanças culturais e, talvez, o próprio estímulo da lei, fizeram com que houvesse um aumento no número de candidatas do gênero feminino. Contudo, a tabela 03 aponta que há muitas candidatas para poucas eleitas, mantendo-se assim o status quo da dominação masculina com uma massiva ocupação das vagas pelos homens.

Assusta o fato de que, percentualmente, o número de eleitas diminuiu drasticamente desde a implementação das cotas. Como se observa da última linha, nas eleições de 2018, sequer 3\% (três) por cento das mulheres que se candidataram foram eleitas. 
Isso conduz a outra percepção. A Tabela 01 aponta que em 2018, o percentual de mulheres candidatas em relação ao total aumentou significativamente, chegando a observar parâmetros estabelecidos pela lei. Contudo, a Tabela 03 revela que nas eleições de 2018, o percentual de eleitas em relação ao número de candidatas foi o menor desde a implementação das cotas. Ou seja, aumentou o número de candidaturas femininas, mas, de acordo com a Tabela 02, o número de candidatas eleitas teve aumento pouco significativo. Uma possível explicação para o fato de que o percentual de candidatas e o percentual de eleitas não aumenta na mesma proporção é que, a fim de garantir uma certa legitimidade às suas candidaturas, os partidos políticos têm cooptado e registrado mulheres como candidatas aos pleitos, sem qualquer preocupação com a sua efetiva eleição através do investimento nas candidaturas. São as chamadas candidaturas "laranja", as candidaturas fraudulentas, que também têm sido alvo de discussão pelos Tribunais Superiores do país ${ }^{8}$. Nas eleições municipais de 2016, estima-se que 14.417 candidatas não receberam sequer um voto (ELOY; SANTANO, 2017, p. 446).

Portanto, acredita-se que os partidos têm lançado mulheres como candidatas apenas para cumprir a cota - objetivo que sequer é alcançado - sem que isso, todavia, signifique em um verdadeiro empenho para que estas sejam eleitas. Essas mulheres não são vistas como participantes ativas, mas sim como figurantes, entrando na disputa eleitoral não para se promoverem, mas sim para pedirem votos para outros candidatos (BERTOT'TI; PEDROSO, 2018, p. 436). Se compararmos os desempenhos das tabelas anteriores com o percentual da população do sexo feminino e com o número de eleitoras, o quadro se agrava. As mulheres compõem quase $52 \%$ (cinquenta e dois por cento) tanto da população quanto do eleitorado brasileiro. Dados de 2019 da Justiça Eleitoral, apontam que há quase 78 milhões de cidadãs registradas, representando 52\% do eleitorado (TSE, 2019).

Tem-se, portanto, que não há uma relação direta entre o número de eleitoras e o número de candidatas e eleitas. Não seria lógico que a representação parlamentar das mulheres se desse na mesma proporção do número de cidadãs? Desde já, descarta-se a tese do "apoliticismo feminino"

\footnotetext{
${ }^{8}$ O termo "apoliticismo feminino" é cunhado por Avelar (2001, p. 88) e, em linhas gerais, significa o desinteresse das mulheres por política. Para a cientista social, os autores que se dedicaram a falar sobre esse tema afirmaram que as mulheres têm um baixo senso de eficácia política e deixaram de considerar fatores importantes como as já mencionadas questões históricas, sociais e culturais, que sistematicamente excluem a mulher da vida pública.
} 
com base em dois elementos já trabalhados. Primeiro, o fato de o número de mulheres candidatas aos cargos eletivos ser drasticamente menor do que o dos homens nada tem a ver com o seu desinteresse. Há fatores históricos, culturais e sociais que afastam a mulher da vida pública de modo geral. Em segundo, o suposto apoliticismo sob o argumento de que "mulher não vota em mulher" também encontra óbice no fato de que os investimentos nas candidaturas femininas ainda são muito inexpressivos, de modo que na campanha eleitoral as mulheres e suas propostas não têm visibilidade. As mulheres candidatam-se sem possuir capital político suficiente, sem desenvolver liderança, sem receber verbas de campanha e sem tempo de propaganda. Portanto, são candidaturas sem qualquer viabilidade eleitoral, o que automaticamente se reflete no número de mulheres eleitas (SANTOS, 2018, p. 27).

Os argumentos, inclusive, vão de encontro com os objetivos das duas leis que tratam especificamente sobre a participação da mulher na política. Em razão da exclusão feminina da esfera pública, instituíram-se as cotas de reserva de candidaturas; em razão da ausência de investimento nas candidaturas femininas, instituíram-se a reserva do fundo partidário e a reserva de tempo na propaganda político-partidária. Desse modo, acredita-se que o sistema patriarcal que permeia a cultura, os hábitos, as leis, as estruturas partidárias e as instituições é o principal responsável pelo descompasso existente entre o número de cidadãs e a representação das mulheres no Poder Legislativo.

Assim sendo, neste momento, a fim de confirmar a hipótese da sub-representação, será feita uma análise nacional das demais casas legislativas do país. Isto é, em termos de dados secundários, serão examinados os percentuais de candidaturas femininas nas eleições para as Assembleias Legislativas do Brasil, bem como das Câmaras de Vereadores, na forma das tabelas abaixo. Além disso, com o objetivo de traçar um comparativo entre eleições que as cotas têm incidência e eleições em que não recaem as cotas, também será analisado o percentual de candidaturas de mulheres para o Senado Federal. 


\subsection{A participação política das mulheres nas Assembleias Le- gislativas, na Câmara de Vereadores e no Senado Federal}

Tabela 04: Percentual Nacional de Mulheres Candidatas para as Assembleias Legislativas a partir da Constituição de 1988 até o ano de 2018

\begin{tabular}{|c|c|c|c|}
\hline Ano & $\begin{array}{c}\text { Total de } \\
\text { Candidatos em } \\
\text { números absolutos }\end{array}$ & $\begin{array}{c}\text { Candidatas Mulheres } \\
\text { em números } \\
\text { absolutos }\end{array}$ & $\begin{array}{c}\text { Percentual de } \\
\text { Candidatas em } \\
\text { Relação ao Total }\end{array}$ \\
\hline $1990^{*}$ & & & 6,15 \\
\hline 1994 & 7.957 & 1.272 & 12,65 \\
\hline 1998 & 10.051 & 1.636 & 14,41 \\
\hline 2002 & 11.346 & 1.602 & 13,94 \\
\hline 2006 & 11.490 & 2.477 & 20,63 \\
\hline 2010 & 11.858 & 4.155 & 18,91 \\
\hline 2014 & 14.308 & 5.633 & 31,39 \\
\hline 2018 & 17.941 & & \\
\hline
\end{tabular}

Fonte: Autora. Adaptação feita com base nos dados de 2018 do Tribunal Superior Eleitoral.

* Durante a coleta dos dados, não foi possível recuperar os dados das eleições para o cargo de deputada/deputado estadual no ano de 1990. Tais dados foram solicitados por e-mail ao TSE, mas, até o fechamento deste trabalho, não se obteve resposta.

A Tabela 4 refere-se às eleições gerais ocorridas no país entre os anos de 1990 a 2018. Na segunda coluna, foram colhidos os números totais de candidatas e candidatos que concorreram ao cargo de deputada e deputado estadual. Em seguida, analisou-se o número total de mulheres candidatas em termos absolutos para, ao fim, formar o percentual de candidatas em relação ao total.

Mais uma vez as cotas foram cumpridas de forma tardia à sua implementação. Até 2014, nenhuma das eleições superou os 30\% (trinta por cento) fixados em lei, que só passou a ser observado nas últimas eleições (2018). Portanto, essa análise permite afirmar que o problema da participação das mulheres no legislativo não ocorre somente em nível federal, mas se repete nas Assembleias Legislativas em nível estadual, o que só reforça a percepção de que a participação das mulheres na política é um problema geral e não específico de alguma localidade.

No item anterior, observou-se o descumprimento da determinação legal por parte dos partidos políticos em nível nacional. Entretanto, a problemática se repete em âmbito estadual. Dessa forma, serão analisados os dados gerais relativos às eleições para as Câmaras de Vereadores. 
Tabela 05: Percentual Nacional de Mulheres Candidatas para as Câmaras de Vereadores a partir da Constituição de 1988 até o ano de 2016

\begin{tabular}{|c|c|c|c|}
\hline Ano & $\begin{array}{c}\text { Total de Candidatos } \\
\text { em Números } \\
\text { Absolutos }\end{array}$ & $\begin{array}{c}\text { Total de } \\
\text { Candidatas } \\
\text { Mulheres }\end{array}$ & $\begin{array}{c}\text { Percentual de } \\
\text { Candidatas em } \\
\text { Relação ao Total }\end{array}$ \\
\hline $1988^{*}$ & & & \\
\hline $1992^{*}$ & & & 18,99 \\
\hline $1996^{*}$ & & & 20,77 \\
\hline 2000 & 371.026 & 70.493 & 22,08 \\
\hline 2004 & 369.024 & 76.655 & 31,89 \\
\hline 2008 & 348.793 & 77.025 & 30,28 \\
\hline 2012 & 420.594 & 134.169 & \\
\hline 2016 & 437.639 & 142.092 & \\
\hline
\end{tabular}

Fonte: Autora. Adaptação feita com base nos dados de 2018 do Tribunal Superior Eleitoral.

* Durante a coleta dos dados, não foi possível recuperar os dados das eleições para o cargo de deputada/deputado estadual no ano de 1990. Tais dados foram solicitados por e-mail ao TSE, mas, até o fechamento deste trabalho, não se obteve resposta.

A Tabela 05 refere-se aos dados gerais das eleições para as Câmaras de Vereadores ao longo dos anos após a promulgação da Constituição de 1988. Num primeiro momento, há o número total de candidatas e candidatos ao cargo de vereadora e vereador no Brasil. Num segundo, apenas o número de candidatas ao cargo de vereadora e, por fim, o percentual de mulheres candidatas em relação ao total. $\mathrm{O}$ desrespeito ao percentual determinado pelo texto normativo repete-se também em âmbito municipal. Ainda que não tenha sido possível localizar os dados das eleições anteriores ao instituto das cotas, interessa investigar o desempenho do percentual de mulheres candidatas no período em que já havia sua previsão legal.

Percebe-se, da análise das duas últimas eleições municipais, que finalmente houve respeito às cotas. De 1997 a 2010, seja na Câmara de Deputados (tabela 01), seja nas Assembleias Legislativas (tabela 04), ou ainda nas Câmaras de Vereadores (tabela 05), não houve uma preocupação dos partidos sequer em atender à determinação instituída pelo legislador.

Somente após decorridos 15 (quinze) anos da promulgação da lei que determinou aos partidos políticos que lançassem pelo menos 30\% (trinta por cento) de candidatas mulheres, houve respeito a tal determinação nas eleições municipais. A regionalização, portanto, parece ser indicativa de aumento na participação das mulheres na política. 
Por fim, cumpre-nos fazer uma última análise do Poder Legislativo brasileiro. Serão examinados os dados relativos aos cargos de senadora e senador, cujas regras eleitorais são distintas e não há incidência das cotas. O objetivo é investigar se o estabelecimento de um percentual mínimo de candidaturas femininas interfere na participação das mulheres na política, ou se, ao contrário, mesmo sem as cotas, o padrão de baixos percentuais de candidatas mulheres se repete.

Tabela 06: Percentual de Mulheres Candidatas para o Senado Federal a partir da Constituição de 1988 até o ano de 2018

\begin{tabular}{|c|c|c|c|}
\hline Ano & $\begin{array}{c}\text { Total de Candidatos } \\
\text { em números } \\
\text { absolutos }\end{array}$ & $\begin{array}{c}\text { Candidatas } \\
\text { Mulheres em } \\
\text { números absolutos }\end{array}$ & $\begin{array}{c}\text { Percentual de } \\
\text { Candidatas em } \\
\text { Relação ao Total }\end{array}$ \\
\hline $1990^{*}$ & & & 7,33 \\
\hline 1994 & 232 & 17 & 12,57 \\
\hline 1998 & 175 & 22 & 15,53 \\
\hline 2002 & 319 & 40 & 15,84 \\
\hline 2006 & 202 & 32 & 13,06 \\
\hline 2010 & 222 & 29 & 20,73 \\
\hline 2014 & 164 & 34 & 17,56 \\
\hline 2018 & 353 & 62 & \\
\hline
\end{tabular}

Fonte: Autora. Adaptação feita com base nos dados de 2018 do Tribunal Superior Eleitoral. *Durante a coleta dos dados, não foi possível recuperar os dados das eleições para o cargo de senador no ano de 1990. Tais dados foram solicitados por e-mail ao TSE, mas, até o fechamento deste trabalho, não se obteve resposta.

A Tabela 6 refere-se à análise dos dados das eleições para o Senado Federal a partir das eleições de 1990, até o ano de 2018. Foram coletados os dados do número total de candidatas e candidatos, em seguida, o número de candidatas mulheres; por fim, o percentual de candidatas em relação ao total. Novamente, os números não refletem uma proporcionalidade em relação ao número de eleitoras e cidadãs. No Senado Federal em que, repita-se, não há incidência das cotas, somente em 2014, pouco mais de $20 \%$ (vinte por cento) entre candidatas e candidatos foram mulheres. Portanto, o que se vê é que ainda se está muito longe de alcançar a igualdade entre homens e mulheres no âmbito político. Nunca houve proporcionalidade entre as candidaturas, muito menos entre os mandatos.

Todos os dados coligidos nas tabelas de 01 a 06 relegam o Brasil ao último país da América do Sul em presença feminina na política, de Resenha Eleitoral (Florianópolis), v. 23, n. 1, p. 231-262, 2019 
acordo com uma compilação feita pela organização internacional União Interparlamentar, cujos dados foram divulgados pelo IBGE. Como visto na Tabela 02, apenas 77 das 513 cadeiras da Câmara de Deputados são preenchidas por mulheres, o que significa um percentual de 15\%. Esses dados relegam o país à $152^{a}$ posição no ranking, dentre 190 (cento e noventa) nações pesquisadas, ficando atrás de países como o Afeganistão (BERTOTTI; PEDROSO, 2018, p. 435).

Analisando os dados apresentados, as regras do sistema eleitoral, o objetivo da Lei de Cotas e dos princípios representativos do Estado Democrático de Direito, observa-se a ausência das minorias políticas em qualquer processo de deliberação pública. Assim "não estamos diante de 'meras' violações de regras constitucionais; são contrariedades insanáveis, que não apenas fissuram, mas rompem a estrutura que sustenta o nosso Estado de Direito, 'ferindo de morte' um dos seus princípios fundamentais, que é a democracia” (FREITAS; COÊLHO, 2016, p. 51).

Portanto, para uma compreensão crítica das limitações ao desempenho das cotas, bem como das motivações que levam à sub-representação das mulheres na política institucional, serão retomadas agora as contribuições da ética do cuidado, que apontam para o caráter patriarcal de como o direito, a política e as leis seguem sendo apresentados.

\subsection{As cotas na política e a participação das mulheres: uma análise pela ética do cuidado}

Conforme já trabalhado, o cuidado como um valor político central, capaz de orientar uma teoria política deve, sobretudo, permitir o desenvolvimento de capacidades e da agência autônoma de todas e todos, de forma responsável e considerando suas interdependências e suas vulnerabilidades, e opondo-se às práticas opressivas e que colocam pessoas e seus grupos em situações de subordinação. Portanto, a partir de agora, cumpre investigar em que medida as cotas para mulheres na política são pensadas a partir dos pressupostos de uma ética do cuidado.

As considerações anteriormente feitas levam à compreensão de que a lei de cotas, na forma atualmente configurada, apresenta uma série de falhas. Ao trabalhar a questão, Kymlicka (2006, p. 307) afirma que a limitação ao sucesso da pretendida igualdade sexual ocorre "pois ela ignora as desigualdades de gênero embutida na própria definição destes cargos". Ou seja, pretende-se que a mulher se insira na política, mas a própria de- 
finição do cargo já pressupõe valores e experiências até então tidas como masculinas. Vale relembrar que ao se falar em valores, experiências e demandas, sejam masculinas ou femininas, a concepção de tais ideais decorre de construções sociais e dos papéis que historicamente foram atribuídos a esses gêneros. Rejeita-se a ideia de "instinto natural" ou de predisposições inerentes ou biológicas.

Afirma-se que a cota por gênero é falha primeiro porque não atinge o objetivo fixado em lei, que é preencher 30\% (trinta por cento) das candidaturas aos cargos para o legislativo de candidatas mulheres. Em segundo lugar, a lei que tem como finalidade permitir e incentivar a efetiva participação das mulheres na política tem a expectativa obstada na análise dos dados, já que, mesmo havendo certo aumento no número de candidatas, isso nem de longe reflete no número de eleitas que efetivamente representem as mulheres, pelo menos simbolicamente.

Fala-se em representação simbólica porque defender a presença de mais mulheres na política não necessariamente garante a defesa de pautas feministas. Entretanto, a pluralidade na composição dos parlamentos é essencial para que as minorias sejam representadas e é um instrumento de inclusão política. De acordo com Young (2006, p. 140), "numa sociedade complexa e com muitos milhões de pessoas a comunicação democrática consiste em discussões e decisões fluidas, sobrepostas e divergentes, dispersas tanto no espaço como no tempo". A autora ainda alerta para o fato de que "a representação política não deve ser pensada como uma relação de identidade ou substituição, mas como um processo que envolve uma relação mediada dos eleitores entre si e com um representante" (YOUNG, 2006, p. 148).

O representante, portanto, não é um substituto daqueles que representa. A terceira onda do movimento feminista trabalhada no primeiro capítulo já fazia a denúncia de que as mulheres divergem substancialmente entre si. Daí porque não se pode exigir, nem mesmo esperar, que a eleição de mulheres no legislativo leve invariavelmente à defesa de pautas feministas. Contudo, pessoas pertencentes ao mesmo grupo social costumam compartilhar de certas percepções e perspectivas particulares. Na lição de Young (2006, p. 175), "cada grupo tem percepções diferentes sobre os demais, e compreensões diferentes sobre a história e a configuração atual das relações sociais". Ademais, a autora acrescenta que "se apenas algumas poucas dessas compreensões influenciam as discussões e as decisões, os atores políticos ficam mais propensos a perpetuar a injustiça ou a agir com imprudência". 
Nesse sentido, defende-se a presença de mais mulheres na política pelo simples fato de que suas experiências, perspectivas e opiniões, moldadas historicamente e construídas socialmente, confere-lhes uma visão não melhor, mas diferente acerca das questões, o que por si só já contribui para o fortalecimento da democracia.

Ainda traçando um paralelo entre as contribuições de uma teoria político-feminista do cuidado e as limitações no desempenho da lei de cotas, pode-se apontar que essa falha decorre primeiramente do fato de que a lei foi elaborada num Congresso Nacional majoritariamente masculino que, ao deliberar sobre os mais variados assuntos, não considera as perspectivas das mulheres, que acabam tendo que competir por papéis, neste caso, os cargos políticos, definidos pelos homens (KYMLICKA, 2006, p. 307). Como foi observado anteriormente, nunca as mulheres representaram a metade do total de parlamentares, mas pelo menos, desde a década de 70, compuseram a metade da população. Nesse sentido, a forma como se instituiu a legislação somente reproduziu os padrões da dominação masculina, já que, ao se determinar o preenchimento de candidaturas, também se aumentou o percentual de vagas em disputa.

O Estado de Santa Catarina, por exemplo, tem direito a 16 (dezesseis) vagas para o cargo de deputada e deputado federal. Sendo assim, se a regra determinasse que cada partido pudesse lançar 100\% (cem por cento) do total de candidaturas, pelo menos 5 (cinco) candidatas deveriam ser mulheres, a fim de respeitar a cota de 30\% (trinta por cento), sobrando 11 (onze) vagas para serem preenchidas por candidatos do gênero masculino. Entretanto, a regra eleitoral autoriza que os partidos lancem até 150\% (cento e cinquenta por cento) de candidatas e candidatos, o que eleva o número para 24 (vinte e quatro). Destes, pelo menos 8 devem ser mulheres. Sobram, então 16 (dezesseis) vagas, que serão preenchidas com maior probabilidade por homens.

Em que medida um legislativo que prevê a adoção de cotas, mas, em contrapartida, aumenta o número total de candidatos para os cargos, fazendo com que mais homens ainda possam se candidatar, está realmente preocupado com a participação das mulheres na política? O Estado, como um ente que deveria ser o garantidor da igualdade material entre homens e mulheres, dessa forma, não adota a responsabilidade derivada do cuidado político como um valor que orienta suas práticas. 
Conforme aponta Kymlicka (2006, p. 304), “os princípios que foram desenvolvidos com as experiências e os interesses dos homens em mente são incapazes de reconhecer adequadamente as necessidades das mulheres ou de incorporar as experiências das mulheres". Se um dos principais motivos que afastam as mulheres do espaço público e, consequentemente da vida política, é o trabalho doméstico, que inclui especialmente a responsabilidade histórica e cultural pela criação dos filhos, para aumentar sua participação na política, os mecanismos jurídicos e as políticas públicas deveriam considerar seriamente esse fato. Trata-se, portanto, de uma vulnerabilidade histórica e cultural, já que se torna muito difícil, na conjuntura política, conciliar campanha eleitoral e, sobretudo, o mandato com os afazeres da vida privada dos quais as mulheres permanecem encarregadas.

De acordo com o IBGE, em casa, as mulheres trabalham o dobro do que os homens. Assim, por essa sobrecarga de trabalho, falta às mulheres o tempo livre, que é o pressuposto básico para o investimento na carreira política. Na lição de Kymlicka (2006, p. 310), “as mulheres estão em desvantagem não porque os homens são favorecidos arbitrariamente na concessão de trabalhos, mas porque a sociedade inteira favorece sistematicamente os homens ao definir trabalhos, mérito etc.".

Por exemplo, a despeito do que determina a legislação trabalhista ${ }^{9}$ acerca da instituição de creches em empresas em que trabalham pelo menos 30 (trinta) mulheres, com mais de 16 (dezesseis) anos de idade, não se vê nenhuma medida nesse sentido sendo adotada ou sequer discutida para as casas legislativas. Não há, portanto, o incentivo anterior e essencial às mulheres para que participem da vida política, pois não se discute culturalmente através de políticas públicas a divisão sexual do trabalho, tampouco se incentiva que o conciliem com a maternidade.

A interdependência das mulheres enquanto grupo, que as coloca efetivamente dependente de ações, políticas públicas, recursos materiais e emocionais, na questão da maternidade, é completamente desconsiderada quando se fala em criar institutos jurídicos que fomentem sua participação na política. Acerca desse tema, Zirbel (2016, p. 219) destaca a importância de políticas públicas para lidar com a desigualdade entre os gêneros após a

\footnotetext{
${ }^{9}$ Art. 389 - Toda empresa é obrigada:

$\int 1^{\circ}$ - Os estabelecimentos em que trabalharem pelo menos 30 (trinta) mulheres com mais de 16 (dezesseis) anos de idade terão local apropriado onde seja permitido às empregadas guardar sob vigilância e assistência os seus filhos no período da amamentação.
}

Resenba Eleitoral (Florianópolis), v. 23, n. 1, p. 231-262, 2019 
gestação. De acordo com a autora, "deve-se levar em conta o fato de que $a$ paternidade, tanto quanto a maternidade, não é algo episódico e demanda o envolvimento e a responsabilidade paterna em atividades de cuidado por vários anos, assim como o apoio da sociedade e suas instituições básicas."

Há, também, vulnerabilidades e dependências biológicas relacionadas ao próprio processo de gravidez, parto e amamentação, que, igualmente, não entram em pauta, porque na discussão e na aprovação da lei, não houve uma preocupação com o contexto relacional de onde os problemas emergiam, em total contrariedade com as contribuições da teoria política do cuidado. São sensibilidades e experiências particulares da vida das mulheres que não foram introduzidas na conjuntura das cotas. Acerca do tema, Kymlicka, citando Richard (2006, p. 308), pontua que "[...] se um grupo é mantido fora de algo por um período suficientemente longo, é avassaladoramente provável que as atividades deste tipo se desenvolvam de maneira inadequada para o grupo excluído.” Ainda, acrescente-se que "[...]; estou firmemente convencida de que se as mulheres estivessem plenamente envolvidas na administração da sociedade desde o início, elas teriam encontrado uma maneira de ordenar trabalho e filhos de maneira que se ajustassem mutuamente."

Assim, a questão da efetiva participação das mulheres na política segue padrões abstratos e universais, mantendo-as em condições de opressão e subordinação na política. Em geral, os papéis de trabalho são definidos de forma a tornarem os homens mais adequados a eles, mesmo em trabalhos "neutros quanto ao gênero. Em suma, "igualdade não pode ser alcançada permitindo que os homens construam instituições sociais segundo seus interesses e, depois, ignorando o gênero dos candidatos ao decidir quem preenche os papéis nessas instituições” (KYMLICKA, 2006, p. 307).

A segunda crítica que se faz à forma como as cotas foram articuladas para efetivar a participação das mulheres na política se relaciona ao momento em que elas incidem. Atualmente, pelo texto legal, o preenchimento por mulheres deve ser feito somente quando do registro das candidaturas. Entretanto, pelos dados representados nas Tabelas 02 e 03, observou-se que garantir um determinado percentual de candidatas interfere pouco ou quase nada no número de eleitas. Vale dizer que o principal meio pelo qual se efetivam direitos e pautas específicas das mulheres são através das propostas legislativas. Isto é, como já defendido, quanto maior a pluralidade na composição do Congresso Nacional, da Assembleia Legislativa ou na 
Câmara de Vereadores, maior é a chance de minorias representativas terem suas demandas efetivamente incluídas no ordenamento político e jurídico.

Por isso, muito se defende que as cotas incidam também nas cadeiras de cada casa parlamentar, de modo que, além de os partidos serem obrigados a preencher um percentual de candidaturas com candidatas mulheres, como já ocorre atualmente, no momento de distribuição das vagas, haja também uma reserva ao gênero feminino. Pela ética do cuidado, esta proposta justifica-se de modo a atender desigualdades históricas e vulnerabilidades culturais. A construção teórica feita ao longo do primeiro capítulo e agora retomada, permite afirmar que homens e mulheres não se encontram em igualdades materiais de condições a disputarem os mesmos cargos. Sobre o tema, Kymlicka (2006, p. 313) defende que "a igualdade requer não apenas igual oportunidade de buscar papéis definidos por homens, mas também igual poder de criar papéis definidos por mulheres ou de criar papéis andróginos, que homens e mulheres tenham igual interesse em preencher". Além disso, "o resultado de tal capacitação poderia ser muito diferente da nossa sociedade ou da sociedade de instituições masculinas com igual oportunidade de ingresso, [...]". Por fim, sustenta o autor que "a partir de uma posição de igual poder, não teríamos criado um sistema de papéis sociais que define os trabalhos 'masculinos' como superiores aos trabalhos "femininos"'.

Sendo assim, pensar em uma proposta que determine que um percentual de cadeiras legislativas seja preenchido por mulheres só corrobora com o objetivo do cuidado enquanto valor político e central. É uma forma responsiva de a parte mais invulnerável da relação, que é o Estado, ainda com fortes traços patriarcais e masculinos, assumir responsabilidades para minar violências, opressões e dominações, e, sobretudo, permitir o desenvolvimento da agência autônoma das minorias políticas, a fim de que o espaço político seja cada vez mais compreendido como possível e permitido às mulheres e, mais ainda, associado à sua "voz diferente".

$\mathrm{Na}$ esteira do objetivo de permitir o desenvolvimento da autonomia plena às mulheres, outra crítica que emerge às cotas por gênero relaciona-se ao percentual. Ora, se as mulheres são mais de metade da população e do eleitorado, porque as cotas limitam-se ao percentual de $30 \%$ (trinta por cento)? Novamente, a fim de reparar as desigualdades históricas e diminuir práticas opressivas, dominadoras e subordinadoras, a ética do cuidado enquanto uma teoria política que oriente todo um projeto de Estado conduz 
ao entendimento de que, pelo menos até se tornarem desnecessárias, as cotas por gênero devem se dar na proporção do gênero do eleitorado, a fim de que os interesses e as experiências das mulheres sejam igualmente importantes na moldagem da vida social. Ou seja, reserva de 50\% (cinquenta por cento) de candidaturas e de vagas.

Assim, se para as eleições à Câmara de Deputados um partido pode lançar 24 candidaturas, propõe-se que, destas, 12 (doze) sejam do gênero feminino e 12 (doze) do masculino. Além disso, se são 513 (quinhentas e treze) vagas em disputa, que pelo menos 256 (duzentas e cinquenta e seis) sejam ocupadas por mulheres. Pela perspectiva do cuidado, o percentual de cotas poderia incidir também nas listas dos partidos, de modo que, se um partido conseguiu 06 (seis) vagas para aquele cargo no parlamento, que pelo menos 03 (três) candidatas a ocupá-las sejam mulheres.

Repete-se que todas essas providências sugeridas são orientadas pelo cuidado enquanto valor central que orienta aquilo que Zirbel (2016) chamou de "medidas políticas para uma sociedade mais justa e democrática". São formas de se combater a violência e a desigualdade entre os gêneros, considerando a vulnerabilidade e a interdependência humanas como elementos centrais e inescapáveis, determinando a assunção de responsabilidades por aqueles grupos que possuem uma maior autonomia em relação aos outros, visando implementar uma sociedade mais justa, democrática e menos negligente (ZIRBEL, 2016, p. 216).

Para tanto, esse processo implica em implementar políticas à organização das instituições e da sociedade que visem à criação de tempo, espaços e maneiras de cuidar, especialmente com a atribuição de responsabilidades entre aqueles que se encontram em posição de dominação. Neste caso, as políticas passam essencialmente pelos homens e por isso, são chamadas de políticas de masculinidade, que "visam neutralizar os passes usados pelos homens para se eximirem das atividades de cuidado e combater, igualmente, a exploração e a violência de um gênero sobre o outro". Além disso, objetiva atingir o âmbito do privado "de fora para dentro", respeitando os arranjos que podem ser estabelecidos pelas pessoas que habitam nesse espaço" (ZIRBEL, 2016, p. 217).

Ou seja, para que as mulheres possam avançar na ocupação do espaço público, onde se localiza a política institucional, é necessário repensar através de práticas de desconstrução "o que é ser mulher”, "o que é ser homem" e "o que é política", construindo-se novas narrativas comporta- 
mentais. Conforme pontua Zirbel (2016, p. 217), é urgente desconstruir o modelo hegemônico de violência e domínio que é comumente apresentado aos meninos e aos homens como algo a ser seguido. Se a política é um espaço ainda masculino, ela também é assim apresentada: como um ambiente de violência e dominação. Daí a dificuldade de as mulheres fazerem parte da política.

Um caminho para a melhoria nos percentuais representados nas Tabelas de 01 a 06, especialmente o que se verifica na Tabela 02, que é o número efetivo de mulheres eleitas para a Câmara de Deputados, é que os homens se voltem para a esfera privada e para aquelas atividades que envolvem cuidados (comumente associadas às mulheres), havendo uma nova divisão nos afazeres domésticos, para que às mulheres sobre tempo livre para a preparação para a vida na política, e para que os homens que já ocupam a política desenvolvam a sua voz moral diferente. Para Zirbel (2016, p. 217) esta prática "visa criar um senso mais agudo de cuidado entre a população masculina" e pode ocorrer através de adoção de algumas medidas: cotas para homens como cuidadores em instituições públicas que visam auxiliar a população em suas atividades de cuidado (creches, escolas primárias, cozinhas coletivas, programas voltados à saúde e à assistência de pessoas em situação de vulnerabilidade acentuada e/ou abrangente etc.); incentivos para trabalhos no âmbito doméstico e possibilidade de remuneração para os mesmos; ou, ainda, inserir tais atividades como alternativas ao serviço militar obrigatório, como forma de atividade cidadã voltada para a coletividade.

Além disso, uma consequência da maior participação dos homens no cotidiano da vida privada, acarretará numa nova forma de compreender os problemas. A "voz diferente", que se preocupa com a rede de relações existentes e com o contexto relacional de onde os problemas emergem, pode ser desenvolvida tanto por homens quanto por mulheres. Entretanto, está mais associada às mulheres porque ela justamente se desenvolve nesse espaço das relações familiares, privadas e de cuidado. Sendo assim, a participação das mulheres na política institucional, que é condição necessária e essencial para uma democracia radical e efetiva, não está somente ligada à ideia de um sistema de cotas, mas passa também pela ideia de cidadania associada ao cuidado e pela desconstrução de antigas práticas e construção de novas narrativas. 


\section{Considerações finais}

O feminismo, não só enquanto movimento, mas também como teoria política, denuncia a dominação masculina ao mesmo tempo em que oferece contribuições para superá-la. Sobre a dominação, atribui a subordinação das mulheres ao sistema patriarcal que permeia a sociedade e suas instituições, impedindo que as mulheres se emancipem, o que por sua vez afeta a sua participação na vida pública, especialmente o protagonismo na política, foco deste trabalho. Já como ensinamento, a teoria política feminista, dentre outros, afirma que se deve valorizar a experiência das mulheres na moldagem da vida social, o que invariavelmente implica em atentar ao mundo privado, buscando diminuir a dicotomia existente com o que se considera mundo público.

Sendo assim, para compreender os motivos da baixa participação das mulheres na política, ainda que exista um mecanismo no ordenamento jurídico que busque aumentar sua participação, este trabalho inicialmente fez uma breve retomada histórica do movimento feminista e suas contribuições, chegando ao desdobramento da teoria político-feminista do cuidado, que afirma que a igualdade material essencial à democracia radical somente será alcançada quando o cuidado for implementado como um valor político central em oposição às práticas de opressão, subordinação e dominação. Para tanto, as vulnerabilidades e interdependências comuns a todas e todos, em maior ou menor medida, deverão ser consideradas na formação das instituições, na definição dos cargos e na elaboração de políticas públicas, redistribuindo-se as atividades de cuidado e as responsabilidades.

Posteriormente, analisou-se o instituto das cotas para mulheres na política, que determina aos partidos políticos que, ao lançarem suas candidatas e seus candidatos para os cargos do Poder Legislativo (à exceção do Senado Federal, cuja eleição é realizada pelo sistema majoritário), incluam, pelo menos, 30\% (trinta por cento) de mulheres em suas listas.

A fim de verificar se as cotas cumprem com o objetivo a que se destinam, isto é, se permitem uma participação efetiva e real das mulheres na política, foi feita uma coleta de dados empíricos das eleições ocorridas no país desde a promulgação da Constituição de 1988.

Os dados, contudo, revelaram um quadro desanimador da participação das mulheres na política, tendo em vista que raramente o percentual determinado em lei foi cumprido. Isto é, seja nas eleições para a Câma- 
ra de Deputados, para as Assembleias Legislativas ou para as Câmaras de Vereadores, poucas vezes as mulheres, que são a maioria da população e do eleitorado brasileiro, representaram 30\% (trinta por cento) do total de candidatos.

Sendo assim, a hipótese inicial não se confirmou. Os indicadores mais concretos da participação feminina, como, por exemplo, o número real de eleitas dentre o total, ou dentre as próprias mulheres, ainda que não sejam o momento de incidência das cotas, apontaram para uma situação ainda pior, em que o percentual de mulheres representantes não chega a $20 \%$ (vinte por cento) do total.

Em suma, concluiu-se que a situação atual das mulheres na política pode ser assim analisada: há mecanismos jurídicos que se apresentam como inclusivos, mas que não são cumpridos. Pelo texto legal, não existe penalidade ao partido político que não cumpre as cotas. Ainda assim, quando o percentual determinado pela lei é observado, o número real de mulheres eleitas é ínfimo quando comparado ao total ou ao número de cidadãs. Mobilizando-se a teoria político-feminista do cuidado para compreender essa situação, constatou-se uma série de limitações às cotas, seja no que tange ao seu percentual, ao momento de sua incidência, à forma como foi elaborada num Congresso Nacional predominantemente masculino, à ausência de punições pelo descumprimento.

Todas essas falhas decorrem do fato de que o feminismo, enquanto teoria política que oferece uma série de contribuições para orientar um projeto de Estado, foi desconsiderado. Isso significa que uma de suas principais contribuições, que é a ética do cuidado, não esteve incluída quando se pensou em criar instituições, políticas públicas, cargos. Ao contrário, manteve-se o status quo patriarcal, fazendo com que as mulheres não conseguissem efetivamente participar da política.

Constata-se que a oportunidade, vaga/cota de participação das mulheres na política não é pensada, proposta ou refletida dentro dos critérios da ética do cuidado, visto que as atribuições para os cargos de natureza pública ou política não levam em consideração a interdependência dos sujeitos, nem mesmo suas vulnerabilidades. Pensar nessa perspectiva resulta em uma pauta em que os ocupantes dos cargos públicos também são sujeitos complexos que possuem suas dependências físicas, sociais, emocionais, sociopolíticas e dependem da estrutura e das relações da esfera privada. 
Refletir a participação das mulheres como candidatas e no exercício dos cargos públicos requer uma desconstrução do papel atribuído ao político-profissional, visto que, historicamente, as habilidades e capacidades "aceitas" socialmente para o exercício são exclusivamente as que valorizam o espaço público, reafirmando a individualidade, a invulnerabilidade do sujeito autodeterminado e que, predominantemente, estariam associados historicamente às características masculinas como força, capacidade de negociação, influência, persuasão, oratória, em detrimento do sexo "frágil" emotivo, pouco racional.

O que se objetiva neste trabalho é reconhecer que, além do desempenho necessário para o exercício do cargo político, as mulheres no processo de construção exercem um duplo movimento, o primeiro por reafirmarem-se enquanto sujeito do espaço privado e o segundo, objeto deste trabalho, o de reafirmarem-se enquanto mulheres no espaço público. Existem inúmeros testes, barreiras, dificuldades e impedimentos que são colocados a todos os candidatos, mas, além dessas dificuldades, existem regras drasticamente impostas às mulheres pela sua única e exclusiva condição de ser mulher.

A democracia, princípio básico do Estado de Direito, necessita qualificar seus representantes, e esta qualificação necessariamente passa por uma construção plural e diversa das identidades no parlamento. Com isso, não se quer dizer que a pauta do movimento feminista esteja necessariamente presente, mas objetiva-se reafirmar que a presença das mulheres, indubitavelmente, seria diferente do atual cenário político do país. A alteração neste quadro é urgente para melhorar a saúde da democracia brasileira. Enquanto minorias não conseguirem representação na política institucional, demandas oriundas de sua própria condição oprimida não serão incluídas em pauta.

Sem dúvidas, mecanismos formais como o direito, a política e as leis são determinantes para construção de novos comportamentos sociais, mas eles não agem sozinhos. O que se propõe, com base na ética do cuidado, é uma transformação política radical, que não se atenha somente em aumentar percentuais de preenchimento de candidaturas ou criar cotas por cadeiras, tampouco em prever penalidades severas. Tal transformação deve passar pela desconstrução dos papéis de gênero através de educação e políticas públicas, e pela ruptura da divisão entre o privado e o público, visando à construção de novas narrativas, pois todas e todos somos interdependentes e estamos vulneráveis a diversas situações. 
A ética do cuidado aponta para o fato de que a política não deve ser encarada como um espaço de violências e opressões, de padrões abstratos orientados pelo sujeito universal do liberalismo. Ao contrário, a política institucional deve ser o primeiro espaço de construção e afirmação da democracia, o que inegavelmente requer a participação das mulheres.

Afinal, a política é um substantivo feminino.

\section{Referências}

BERTOT'TI, Bárbara Mendonça; PEDROSO, Priscila Stela. Candidatas de fachada: entre invisibilidade e machismo. In: SALGADO, Eneida Desiree; KREUZ, Letícia Camargo; BERTOTTI, Bárbara Mendonça (Org.). Mulheres por Mulheres: Memórias do I Encontro de Pesquisa por/de/sobre Mulheres. Porto Alegre: Fi, 2018. p. 435-436.

FREITAS, Juliana Rodrigues; COÊLHO, Lorraine Ferreira. Eleições municipais 2016 e a frustração diante da inoperância do sistema de cotas. In: SALGADO, Eneida Desiree; KREUZ, Letícia Camargo; BERTOTTI, Bárbara Mendonça (Org.). Mulheres por Mulheres: Memórias do I Encontro de Pesquisa por/de/sobre Mulheres. Porto Alegre: Fi, 2018. p. 35-53.

GILLIGAN, Carol. Uma voz diferente. Psicologia da diferença entre homens e mulheres da infância à fase adulta. Rio de Janeiro: Rosa dos Tempos, 1982.

KYMLICKA, Will. Filosofia política contemporânea: uma introdução. São Paulo: Martins Fontes, 2006. 1 v. Tradução de: Luís Carlos Borges.

KUHNEN, Tânia Aparecida. A ética do cuidado como alternativa à ética de princípios: divergências entre Carol Gilligan e Nel Noddings. Florianópolis, v. 9, n. 3, p. 155-168, set. 2010. ISSN 1677-2954. Disponível em: <https:// periodicos.ufsc.br/index.php/ethic/article/view/1677-2954.2010v9n3p155>. Acesso em: 04 mar. 2019.

MIGUEL, Luis Felipe; BIROLI, Flávia. Feminismo e Política: uma introdução. São Paulo: Boitempo, 2014. 164 p.

MOISÉS, José Álvaro; SANCHEZ, Beatriz Rodrigues. Representação política das mulheres e qualidade da democracia: o caso do Brasil. In: O Congresso Nacional, os partidos políticos e o sistema de integridade: representação, participação e controle institucional no Brasil contemporâneo[S.l: s.n.], 2014. 
MOUFFE, Chantal. O regresso do político. Lisboa: Gradiva, 1996.

OLIVEIRA, Rosiska Darcy de. Elogio da Diferença. O Feminino Emergente. São Paulo: Brasiliense, 1999.

SANTOS, Magda Guadalupe dos. O feminismo na história: suas ondas e desafios epistemológicos. In: BORGES, Maria de Lourdes; TIBURI, Márcia. Filosofia: machismos e feminismos. Florianópolis: UFSC, 2014. Cap. 7. p. 129-176.

SIQUEIRA, Camilla Karla Barbosa. As três ondas do movimento feminista e suas repercussões no direito brasileiro. In: XXIV CONGRESSO NACIONAL DO CONPEDI, 2015, Belo Horizonte. Poder, cidadania e desenvolvimento no Estado Democrático de Direito, 2015. p. 328 - 354. Disponível em: <https://www.conpedi.org.br/publicacoes/66fsl345/w8299187/ ARu8H4M8AmpZnw1Z.pdf>. Acesso em: 13 jul. 2019.

TIBURI, Márcia. Feminismo em comum: para todas, todes e todos. 3. ed. Rio de Janeiro: Rosa dos Tempos, 2018. 126 p.

TRONTO, Joan C. Assistência democrática e democracias assistenciais. Sociedade e Estado. Brasília, vol. 22, no2, agosto 2007. Disponível em: http:/ /www.scielo.br/scielo.php?script=sci_arttext\&pi$\mathrm{d}=$ S0102-69922007000200004\&lng=en\&nrm=iso. Acesso em: 05 jul. 2019.

YOUNG, Iris Marion. Representação política, identidade e minorias. Lua Nova, São Paulo, n. 67, p. 139-190, 2006. Disponível em: <http:/ /www. scielo.br/scielo.php?script $=$ sci_arttext\&pid=S010264452006000200006\&ln$\mathrm{g}=$ en\&nrm=iso $>$. Acesso em: 15 maio 2019.

ZIRBEL, Ilze. Uma teoria político-feminista do cuidado. 2016. 260 f. Tese (Doutorado) - Curso de Filosofia, Filosofia e Ciências Humanas, Universidade Federal de Santa Catarina, Florianópolis, 2016. Disponível em: <https://repositorio.ufsc.br/bitstream/handle/123456789/167820/339912. pdf? sequence=1\&isAllowed $=\mathrm{y}>$. Acesso em: 12 jul. 2019.

Betina Fontana Piovesan - Bacharela em Direito pela Universidade do Vale do Itajaí UNIVALI (2018); Mestranda em Teoria e História do Direito no Programa de Pós-Graduação em Direito pela Universidade Federal de Santa Catarina - PPGD/UFSC (atual), com enfoque em historicismo, conhecimento crítico e subjetividades. Pesquisadora do Lilith: Núcleo de Pesquisa em Direito e Feminismos/CNPq. 